\title{
Revisiting Industry 4.0 with a Case Study
}

\author{
Jiangning Chen \\ Siemens Corporation Technology \\ shanghai, China \\ (jiangning.chen@siemens.com)
}

\author{
Jiehan Zhou (member, IEEE) \\ University of Oulu, Finland \\ Oulu, Finland \\ jiehan.zhou@oulu.fi
}

\begin{abstract}
The Industry 4.0 is becoming a hot topic. In this paper, we revisit Industry 4.0 from the perspectives of its purposes, features, and key performance indicators. We present a reference roadmap for advancing an Industry 4.0 project from plan to implementation. We present the case study of steel industry 4.0 and lessons. In addition, we give suggestions directing the advancement of Industry 4.0.

Keywords - Industry 4.0, Made in China 2025, Intelligent Manufacturing, Industrial Internet
\end{abstract}

\section{INTRODUCTION}

The development of information and communication technologies is deepening the revolution of manufacturing industry and endowing intelligent manufacturing with digitalization, networking, and intelligence.

At Hannover Fair 2013, the German government officially presented "Industry 4.0" for promoting the computerization of manufacturing [1]. The following annual Hanover Fair showed Industry 4.0 in the reality of digital factory, logistics combining with complete automation solution, advanced robot, etc. In addition, there exhibited Industry 4.0 operating systems such as Siemens Mindsphere [2] and General Electric (GE) Predix [3]. According to stats [4], Hannover Fair 2017 attracted 225,000 visitors all over the world.

In 2015, the China State Council issued the whitepaper of "Made in China 2025" for guiding Chinese enterprises to improve their productivity and efficiencies [5]. In 2017, China Aerospace Science and Industry Corporation developed China first industrial Internet platform, INDICS [6], which is an industrial Internet platform with the orientation to manufacturing cloud, targets at the innovation of manufacturing technologies and builds a new industrial Internet ecosystem.

At present, there coexists different manufacturing grades in the forms of mechanization, electrification, automation, and informatization in the world, e.g., China. How to properly comprehend the opportunity of Industry 4.0 and upgrade manufacturing industry becomes an urgent issue. We regard Industry 4.0 as the result of the deeper integration of emerging information communication technology, especially, Internet of things [7, 8], 5G [9] and Big Data [10, 11] with the manufacturing industry. Industry 4.0 emphasizes the combination of digital know-how management, people, equipment, and material, and using an unified operating platform to transparently manage customer relationships, production processes, information flows and logistics.

Zhong et al. reviewed academic work on intelligent manufacturing from 2005 to 2016 [12]. The results showed that the top five publishers are the International Journal of Advanced Manufacturing Technology, Computer Integrated Manufacturing Systems, Journal of Intelligent Manufacturing, International Journal of Production Research, and Expert Systems with Applications. The top five universities are Shanghai Jiao Tong University, Beihang University, Zhejiang University, Chongqing University, and Tsinghua University. The top active countries or regions are China, the United States, and the United Kingdom.

The remainder of the paper is organized as follows. Section 2 revisits Industry 4.0 from perspectives of purposes, features, Key Performance Indicator, and discrete and process Industry 4.0. Section 3 presents a roadmap towards the implementation of Industry 4.0. Section 4 studies a case of steel Industry 4.0. Section 5 presents the lessons. Section 6 concludes the paper and gives suggestions directing the Industry 4.0 implementation.

\section{REVISITING INDUSTRY 4.0}

\section{A. Concepts}

GE first termed Industrial Internet as a concept of integration and linking big data, analytical tools and wireless networks with physical and industrial equipment [13]. Recently, the Industrial Internet is embracing ideas of intelligent objects with embedded technology and the Internet of Things (IoT) [14]. Industrial Internet is the antecessor term of Industry 4.0.

Figure 1. The three-dimensional benefits of Industry 4.0

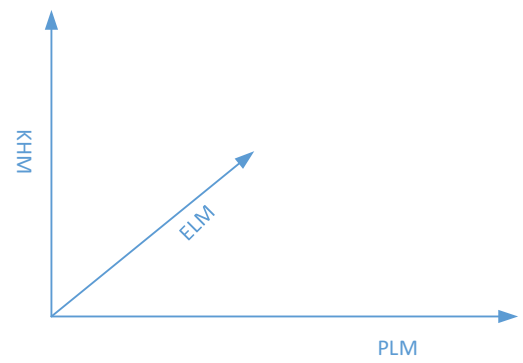

We define Industry 4.0 as data-driven network manufacturing system with the full integration of information technology (IT) and operation technology (OT) (Fig. 1). The premise of Industry 4.0 is enterprise digitalization based on mechanization, electrification and automation. That is, Industry 4.0 can greatly improve connectivity, efficiency, scalability, time saving, and cost saving in the dimensions of equipment life cycle management (ELM), product life cycle management (PLM) and enterprise know-how management (KHM). 
PLM dimension. Industry 4.0 expects to have a unified platform for PLM from market analysis, conceptual design, preliminary design and detail design, process design, performance verification, small-scale and mass production, manufacturing, sales, to customer feedback. Among them, product performance simulation, virtual assembly and virtual manufacturing are expected to be done based on $3 \mathrm{D}$ product model. The product document delivery to the manufacturing factory is also based on digital product data.

ELM dimension. ELM includes a complementary mix of condition-directed, time-based and, even run-to-failure maintenance when justified. For enabling maximum equipment gains, Industry 4.0 should digitalize factory, process and equipment, and real-time monitor their operational statuses, such as planned maintenance and predictive equipment maintenance. Industry 4.0 could apply 3D modeling into key equipment or dangerous processes to achieve on-site equipment maintenance.

KHM dimension: Know-how includes all knowledge and expertise for a product such as design drawing, production knowledge and skills. The standardization, digitization and maintenance of know-how are important for enterprise to share and aggregate data, and improve enterprise efficiency. The socalled "hundred-year-old shop" also means that the enterprise know-how must be well integrated and inherited. Industry 4.0 expects to digitalize the enterprise know-how so that it is easier to be integrated and inherited for the upgrading of a manufacturing system.

\section{B. Purposes}

There are many countries, which have launched national strategic plans for manufacturing, such as Industry 4.0 and Made in China 2025. Their core purpose is to improve the productivity and efficiencies in the production process and throughout the supply chain, further promote their product competitiveness. Data-driven Industry 4.0 is the right solution and enables enterprises to obtain predictive maintenance, safety, and other operational efficiencies for achieving highquality products, efficient use of resources, and rapid market response.

Industry 4.0 emphasizes high efficiency, fast response, and high quality. To achieve this goal, Industry 4.0 requires not only upgrading software and hardware, but also changing management methods and values of manufacturing products. Industry 4.0 enables people to make decisions based on data, make decisions traceable through data optimization. Therefore, Industry 4.0 aims to make lean management, process standardization, knowledge systemization through big data analysis and data transmission transparency. Essentially, Industry 4.0 enables a consistent and systematic management from production, sale to design through effectively integrating the IT and OT system so that it reduces management levels and human intervention in production.

\section{Features}

Industry 4.0 has the following features:

- Digital know-how management, data transparency, system optimization, unified production management platform;
- Connect and integrate people, equipment and systems into the entire product value chain;

- All relevant data and information can be obtained dynamically across product suppliers, producers and customers;

- Each value chain can be continuously optimized based on merits such as costs, resources, and customer needs;

- Lean management, data standardization, data-driven added value and data-driven decision-making.

D. Key performance indicator (KPI)

The main KPIs for Industry 4.0 are as shown in Fig. 2. They are the time to market, flexibility, resource efficiency, and product quality. Data-driven Industry 4.0 expects to address those KPIs by integrating highly fragmented data generated in different product processes. By customizing and optimizing product design, Industry 4.0 timely provides customers with their needs; Industry 4.0 guarantees safe and reliable operation of equipment by real-time monitoring their states; Industry 4.0 improves productivity, efficiency and product quality by optimizing production processes.

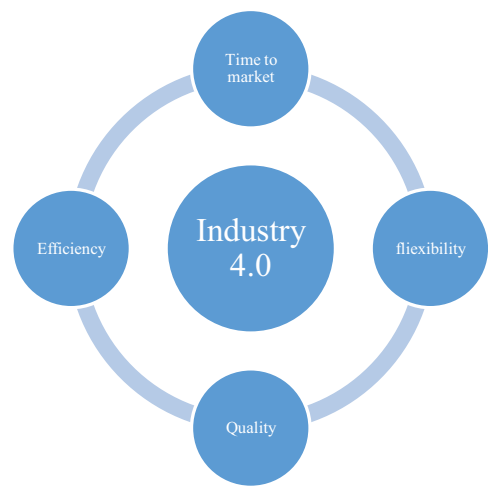

Figure 2. KPIs for Industry 4.0

\section{E. Discrete and process Industry 4.0}

Discrete industry is the production of distinct products. Automobiles, furniture, toys, smartphones, and airplanes are the examples [15]. Discrete industry has the complexity of production process and production equipment. Discrete Industry 4.0 emphasizes the interconnection of production equipment, the visualization of production data, the digitalization of production document, the transparency of the production process with the end-to-end integration for achieving high quality, high-efficiency, and flexible production.

Process industry is the industry where the primary production processes are either continuous, or occur on a batch of materials that is indistinguishable. The process industry is mostly a raw material processing enterprise. For example, a steel company. The output of the process industry mainly depends on the capabilities of the equipment. The quality of its products mainly depends on the precise control of equipment and processes. Digital process and management are considered as primary paths for the process Industry 4.0 to improve its performance. The current solution to discrete Industry 4.0 requires special modifications in order to adapt to the process Industry 4.0. Overall, the implementation of process Industry 4.0 is just a start. 


\section{ROADMAP FOR IMPLEMENTING INDUSTRY 4.0}

Fig. 3 illustrates our designed roadmap for implementing Industry 4.0. The implementation covers the planning, construction and operation of digital factory. It is a systematic task involving many information systems, various sets of equipment and personnel in various positions. Industry 4.0 introduces intelligent applications into digital factory so that each unit is connected and integrated on the basis of real-time monitoring and predictive maintenance. Digital know-how management of Industry 4.0 enables organizations to break data silos and connect people, product, equipment and processes from the factory floor to the executive officers to achieve continuous steady improvement of management. Concretely, roadmap for implementing Industry 4.0 covers three major phases:

- Analyze current situation for identifying business goals, development, operation and management, and understand existing questions and differences between now and future.

- Plan business modules such as Industry 4.0 functions, system architecture, system security, and plans for product/equipment/know-how management.

- Implement Industry 4.0 such as business module definition, module priority analysis, feasibility analysis, detail steps for industry 4.0 implementation.

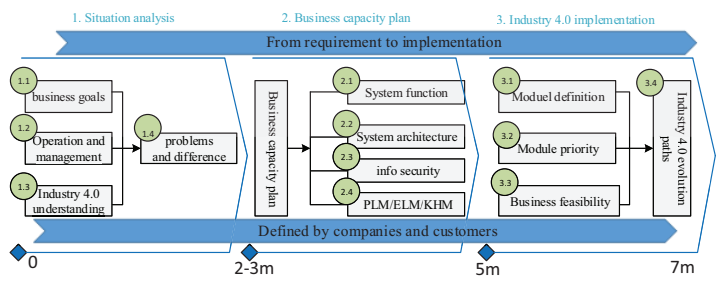

Figure 3. Roadmap for implementing Industry 4.0

Based on our experience, there are tips for companies to implement Industry 4.0 as the follows.

The first is to build so called top leadership project, which requires a team from top leader to general staff to have a unified understanding of Industry 4.0. Further, the team should distinguish Industry 4.0 from conventional technological transformation and emphasize its implementation as a top-level strategy for the company.

The second is to organize a special team to implement pilot projects through collecting certain financial resources and people, optimize and integrate internal and external resources, and fully maneuver the employees from middle and lower levels of the company.

Then, a company must define the KPIs and pilot projects in accordance with Industry 4.0/Made in China 2025 standards. Both the implementation of Industry 4.0 and its long-term plan should be based on the company's blueprint.

Then, a company should consolidate the Industry 4.0 solution that could form standards for application and industry.

Finally, a company should cooperate with system integrators, end users, platform providers to promote and mature the Industry 4.0 solutions.
Industry 4.0 is widely considered to be the primary force reviving industrial businesses today. Its implementation and deployment need a long-term plan. Fig. 4 outlines general steps from Industry 2.0 to Industry 4.0 suitable for different fields.

It must be emphasized that Industry 4.0 is not only a upgrade of software and hardware, but also a change in enterprise culture, data standardization organizational structure, lean management, and people. By studying digital factories and physical factories, the ultimate goal of Industry 4.0 is to achieve the integration of PLM/ELM/KHM into virtual factories and make virtual factories to interact with physical factories. Physical factory is responsible for production, operations, logistics, and virtual factory is responsible for optimization, simulation, verification, and know-how management and delivery.

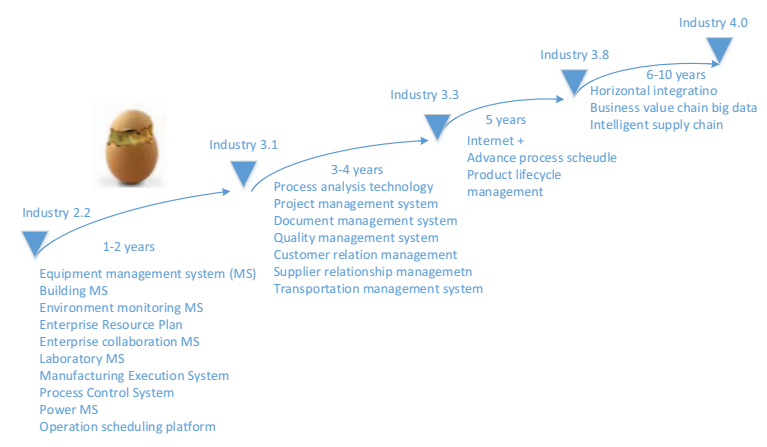

Figure 4. Steps towards Industry 4.0

\section{CASE STUDY: STEEL INDUSTRY 4.0}

\section{A. Digital steel industry architecture}

Through company assessment, we found that a typical steel company lacks a unified platform for product life cycle and equipment life cycle management. Fig. 5 illustrates our designed architecture for implementing steel Industry 4.0. Currently, there is a lack of practice of digitization and standardization. There is also a lack of practice in know-how modeling and digital storage. There is a lack of mechanisms for such as less humanization/unmanning operations in high-intensity or harsh environments, and quality management in big data, which are obstacles for hindering company competitiveness. With the support of the general digital architecture, we achieved two use cases as follows.

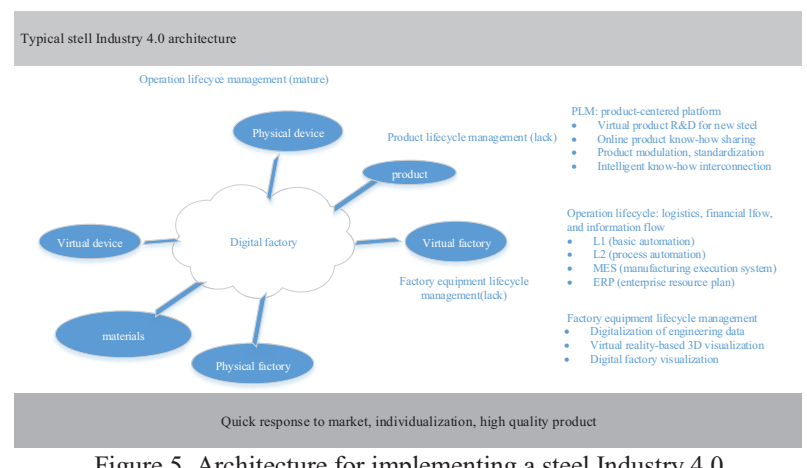

Figure 5. Architecture for implementing a steel Industry 4.0

User case $1-$ a wireless solution to liquid steel transportation for torpedo production. Generally, the transportation is dangerous and labor costing so that it is important to build up a complete solution to unmanned 
operation in the context of smooth and secure data transmission. In practice, we provide an integrated wireless solution including RFID, 4G, WLAN, RNA (redundant Network Access), Wi-Fi, to build up a reliable wireless data communication platform to enable the access to data produced in different operation courses.

User case 2 - an oil-filling robot for grinding steel roller, which uses the technology of robot, machine vision, RFID, and robot control programs to fill oil by following shift schedules from the MES (manufacturing execution system) in grinding workshop. Machine vision captures the hole position of a roller for filling oil and makes sure that the filling is accurate. RFID identifies the types of roller and decides which oil should be filled. After using the filling automation solution, we save two persons for each grinding workshop and the solution is ready to serve other customers.

\section{B. Unified digital design and operation platform}

We designed the unified digital design and operation platform. The platform provides digital documents instead of traditional blueprints, which breaks data silos and facilitates data flows through process chains. Modifying one piece of data will also be refreshed in other places. The digital documents for plants and equipment can be used for building their 3D models, which could be applied into operation training and maintenance with the use of virtual reality.

\section{C. intelligent visualization}

In the steel industry, we designed an intelligent visualization platform, which presents enterprise decision-making layers with comprehensive and quick comprehensive information on workshops, MES and ERPs, which is helpful to facilitating decision-making on operations, finance, and marketing.

\section{PLM lifecycle management}

The product lifecycle management is the core of Industry 4.0. It uses the product as the object to incorporate all product information, from requirements, conceptual design, preliminary and detail design, simulation, process, manufacturing to product sale and user experience into a unified platform. Among them, the BOM - bill of materials plays a very important role in customizing production. The steel industry has applied the process mathematical model in its control. Its main purpose is to specify process parameters based on products and processes.

\section{E. ELM lifecycle management}

At present, most of the process industry have implemented ELM systems based on equipment code. In the transformation of Industry 4.0, we regard that ELM should be object-oriented, rather than simple equipment code management. Objectoriented ELM covers information on equipment-related design, manufacturing, and operation and maintenance.

\section{LESSONS}

According to the Industry 4.0 practice with customers for more than two years, we gained the following lessons.
The Industry 4.0 implementation is a gradual process. It needs an overall plan and takes into account the cooperation among PLM, ELM, ERP and KHM. It is recommended that enterprises should focus on their implementation based on their own actual needs and conditions. Enterprises increase courage and confidence by making an initial digital system and benefiting from it. Therefore, enterprises gradually realize the transformation from traditional production to digital enterprise and intelligent production.

The Industry 4.0 implementation is a process of digital factory construction with the combination of new management and new technology. It makes full use of modern information communication technologies to integrate IT systems and OT systems for reorganizing enterprises rather than simply replacing personnel with computers and writing traditional management into computer networks. Therefore, Industry 4.0 requires a special team for guaranteeing the successful implementation and continuous development of digital factory. The team consists of a combination of management personnel, business leader, and technical personnel or external consultants.

It is important for enterprises to train Industry 4.0 personnel from the decision-making level administrator to workshoplevel worker. The attention should be paid to the implementation of digital factory by administrative leader, business manager and operational worker.

The Industry 4.0 implementation is a long-term digitization and informatization for enterprises. There needs a long-term adjustment and coordination between information systems and operation systems due to the influence of the external environment and internal factors.

\section{CONCLUSION}

Industry 4.0 promises to revolutionize manufacturing by enabling the integration of ITs and OTs through the acquisition and accessibility of far greater amounts of data, at far greater speeds. How to understand Industry 4.0 is important for guiding its implementation for promoting manufacturing productivity and efficiency. We regard Industry 4.0 as digital data-driven network information systems in manufacturing industry for supporting product lifecycle management, equipment lifecycle management and know-how management. Industry 4.0 makes use of a unified collaborative platform to transparently manage production, process, logistics, and data flow, emphasizing the combination of knowledge management, people, machines, and materials. In this paper, we revisit Industry 4.0 from perspectives of concepts, purposes, features, KPIs, discrete and process Industry 4.0. We design a reference roadmap for implementing Industry 4.0. We examine a case study of a steel Industry 4.0 and lessons gained. There are suggestions for advancing Industry 4.0 in the future.

- Improve the policy of supporting technological innovation such as state-owned engineering research centers, key laboratories, and encourage them to research and develop 
intelligent manufacturing systems with the manufacturing industry.

- Establish specifications and standards for intelligent manufacturing, which are inseparable from the concrete practice and support of pilot projects.

- Pay high attention to manufacturing personnel training, who master expertise at sociology, economics, and humanities, and artificial intelligence as well.

- Enhance international exchanges and cooperation. This examined project of Joint Baowu Siemens Industry 4.0 Exploration is a good example of China-German cooperation in intelligent manufacturing implementation and Industry 4.0 standards.

\section{REFERENCES}

[1] H. Kagermann, W. Wahlster and J. Helbig, eds., 2013: Recommendations for implementing the strategic initiative Industrie 4.0: Final report of the Industrie 4.0 Working Group.

[2] Mindsphere, The Internet of Things (IoT) Solution, Retrieved from https://www.siemens.com/global/en/home/products/software/mindsphe re.html. 25.03.2018.

[3] Predix, The Foundation for Digital Industrial Applications, Retrieved from https://www.ge.com/digital/predix-platform-foundation-digitalindustrial-applications. 25.03.2018.

[4] Hannover Messe, Retrieved from http://www.hannovermesse.de/home. 25.03.2018.

[5] The State Council of China, Chinese enterprises take 'Made in China' to new level, Retrieved from http://english.gov.cn/news/video/2016/08/27/content_2814754270206 47.htm. 25.03.2018.

[6] INDICS. INDICS - China Leading Industrial Internet, Retrieved from http://intl.indics.com/, accessed by 18.03.2018. 25.03.2018.

[7] J. Zhou, T. Leppanen, E. Harjula, et al. Cloudthings: A common architecture for integrating the internet of things with cloud computing. In IEEE 17th International Conference on Computer Supported Cooperative Work in Design (CSCWD), pp. 651-657, 2013.

[8] SuperIoT. A Finland-based alliance of $150+$ companies, Retrieved from https://www.superiot.fi/. 25.03.2018.

[9] 5G Test Network, Retrieved from https://5gtn.fi/. 25.03.2018.

[10] M. Chen, J. Yang, J. Zhou. 5G-Smart Diabetes: Towards Personalized Diabetes Diagnosis with Healthcare Big Data Clouds. IEEE Communications Magazine. IEEE Communications, Vol. 56, No. 4, pp. 2-9, April 2018.

[11] W. Zhang, Y. Zhang, J. Zhai, D. Zhao, L. Xu, J. Zhou, Z. Li, S. Yang, Multi-source data fusion using deep learning for smart refrigerators, Computers in Industry, Vol. 95, pp. 15-21, 2018.

[12] Ray Y. Zhong, Xun Xu, Eberhard Klotz, Stephen T. Newman, Intelligent Manufacturing in the Context of Industry 4.0: A Review, Engineering, Vol. 3, No. 5, pp. 616-630, 2017.

[13] Techopedia, What does Industrial Internet mean? Retrieved from https://www.techopedia.com/definition/30044/industrial-internet, 18.03.2018.

[14] S.Jeschke, C.Brecher, T.Meisen, D. Özdemir, T. Eschert. Industrial internet of things and cyber manufacturing systems. In: Jeschke S., Brecher C., Song H., Rawat D. (eds) Industrial Internet of Things. Springer Series in Wireless Technology. Springer, Cham, pp. 3-19, 2017.

[15] JD Edwards World. Product Data Management - Discrete Guide. Retrieved from https://docs.oracle.com/cd/E26228_01/doc.93/e21777.pdf, 25.03.2018. 